\title{
PERANCANGAN SISTEM PAKAR MINAT MAHASISWA BERDASARKAN KURIKULUM PROGRAM STUDI TEKNIK INFORMATIKA UNIVERSITAS XYZ
}

\author{
Budi Arifitama \\ Teknik Informatika, Universitas Trilogi \\ J1. Kampus Trilogi /STEKPI No.1 \\ E-mail: budiarif@universitas-trilogi.ac.id
}

\begin{abstract}
In this modern days, various professions exists, especially in the field of information technology, college students tends became confused and struggle on which profession should the student take after their graduation, students are still undecided in determining their interest in the IT profession as well as subjects that support the direction of the profession. Based on these problems, I created an expert system to determine the requisition for the students to match the profession of IT in accordance with the existing curriculum in informatics engineering at the university xyz.
\end{abstract}

\section{Abstrak}

Beragam profesi di dunia kerja khususnya di bidang teknologi informasi menjadi momok tersendiri bagi mahasiswa di perguruan tinggi. Mahasiswa memiliki kesulitan dalam menentukan profesi apa yang mereka akan geluti setelah kelulusan, mahasiswa masih bimbang dalam menentukan minat bidang profesi di TI serta matakuliah yang mendukung ke arah profesi tersebut. Berdasarkan permasalahan tersebut, dibuat sebuah sistem pakar untuk menentukan perminatan mahasiswa pada profesi dunia kerja TI sesuai dengan kurikulum yang ada di program studi teknik informatika universitas xyz.

Kata kunci: Sistem pakar, perminatan TI

\section{PENDAHULUAN}

Dunia kerja adalah salah satu tahapan setelah kelulusan yang harus dihadapi oleh mahasiswa dari perguruan tinggi, hadirnya jenis pekerjaan yang sangat beragam pada industri informatika seperti programmer, administrator jaringan, sistem analis, serta jenis pekerjaan lainnya, menjadikan mahasiswa cenderung memiliki kesulitan dalam menentukan bidang profesi mana yang ingin mereka geluti. Hal ini berdampak pada alur perkuliahan mahasiswa pada saat menjalani perkuliahaan di perguruan tinggi. Sistem pakar adalah sistem yang berusaha mengadopsi pengetahuan manusia ke komputer, agar dapat menyelesaikan masalah seperti yang bisa dilakukan oleh para ahli. Dalam hal ini, sistem pakar digunakan untuk membantu mahasiswa, untuk mendapatkan gambaran profesi mana yang cocok bagi mahasiswa yang tentunya mengacu pada kurikulum program studi teknik informatika.

Pada dasarnya ide pembuatan dari sebuah sistem pakar adalah mengadopsi hasil dari pemikiran dan pengetahuan dari manusia ke dalam sebuah alat komputasi yaitu komputer, untuk menghasilkan sebuah solusi dari sebuah permasalahan yang timbul. Inti dari sebuah sistem pakar berada pada proses generate yang dilakukan pada saat dilakukan pemakaran. Peran pemilihan sebuah metode yang digunakan dalam sistem pakar menjadi penting, penggunaan metode yang tepat menentukan ketepatan dan keakuratan dari solusi yang ditawarkan kepada user sebagai pengguna. Menurut Giarratano dan Riley, sistem pakar adalah salah satu cabang kecerdasan buatan yang menggunakan pengetahuan khusus yang dimiliki oleh seorang ahli untuk menyelesaikan suatu masalah tertentu.

Metode yang digunakan pada penelitian adalaha metode binary tree digunakan sebagai metode penelusuran pengetahuan dari sistem pakar. Berdasarkan permasalahan yang ada, maka penulis melakukan penelitian pembuatan perancangan sistem pakar untuk membantu mahasiswa menentukan perminatan mengacu kurikulum di universitas xyz.

\section{METODOLOGI}

Sebagai upaya penyelesaian permasalahan dari penelitian, metode pelacakan yang digunakan dalam penelitian untuk pembuatan aplikasi sistem pakar perminatan mahasiswa adalah 
menggunakan Forward Chainning. Forward chaining merupakan sebuah metode pencarian/ penarikan kesimpulan yang berdasarkan pada data atau fakta yang ada menuju ke kesimpulan, penelusuran dimulai dari fakta yang ada lalu bergerak maju melalui premis-premis untuk menuju ke kesimpulan. Jika klausa premis sesuai dengan situasi, maka proses akan memberikan kesimpulan akhir. Dari penjelasan diatas, didapatkan bahwa konsep pergerakan atau penelusuran yang di ilustrasikan pada gambar 1 , dari metode forward chaining adalah dengan menelusuri premis satu per satu secara bertahap, dimana setiap tahap diwakilkan oleh premis sebagai penghubung ke premis lainya sesuai dengan fakta yang dimiliki oleh pengguna untuk memberikan hasil solusi akhir yang dapat dimanfaatkan oleh pengguna. Sebagai gambaran dari pola kerja forward chaining, binary tree pada gambar 2 digunakan sebagai pemodelan dari premis yang digunakan, dimana node awal yaitu root, adalah tahapan awal dari proses penelusuran dimana dengan menggu-nakan binary tree tentunya hanya terdapat 2 jalur yang dapat dilalui hingga penelusuran paling akhir yang memberikan rekomendasi solusi kepada pengguna.

\section{HASIL dan PEMBAHASAN}

Sistem pakar memerlukan komponen pengetahuan/knowledge, adapun perancangan knowledge dari sistem pakar sendiri dilakukan dengan cara mendapatkan pengetahuan dari pengalaman pribadi serta menanyakan langsung kepada pelaku industri TI mengenai kebutuhan dari beberapa profesi yang ada di TI. Berdasarkan kurikulum program studi, terdapat 9 jenis profesi yang dapat dijadikan acuan yaitu IT support, umum, network engineer, web developer, programmer, web design, system analyst, quality assurance, database administrator.
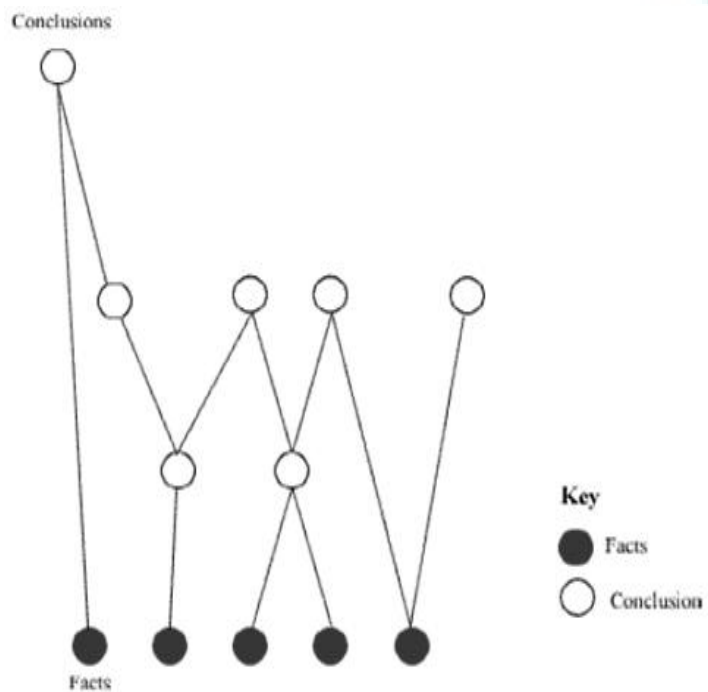

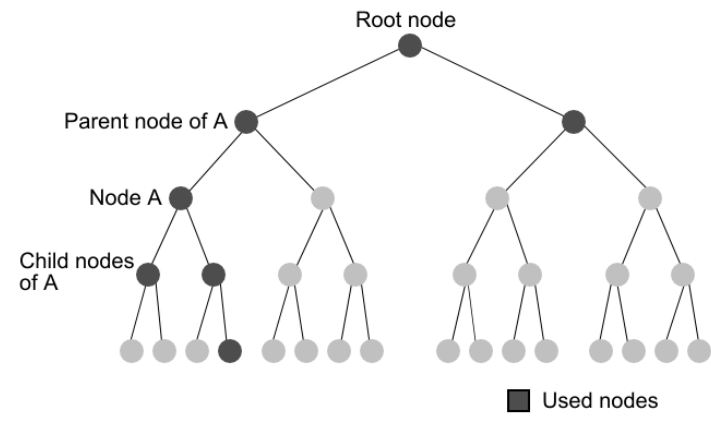

An example of a binary tree

Potential nodes

Gambar 2. Contoh Binary Tree

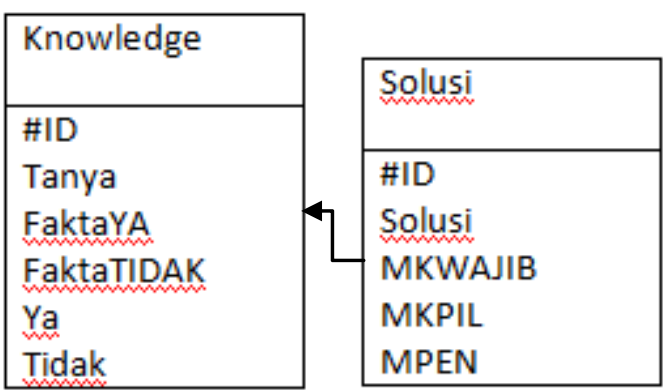

Gambar 3. Skema Logika Basis Data

\subsection{Perancangan Basis Data Sistem Pakar}

Perancangan basis data pada aplikasi sistem pakar pada penilitian ini sangat sederhana, dimana percancangan menggunakan logical design dan physical design. Basis data pada sistem pakar hanya untuk menyimpan data knowledge dari premis dan solusi. Pada tahapan perancangan skema basis data yang pertama logical design, digunakan konsep relational database.

Dari hasil ilustrasi gambar 3, terdapat dua tabel yang saling tekait, yaitu tabel knowlwdge dan tabel solusi. Tabel pertama yaitu knowledge berisikan D, Tanya, Fakta YA, Fakta TIDAK, Ya, dan Tidak, dimana pembentukan dari sebuah knowledge diperuntukan sebagai penyimpanan fakta dan premis dari sistem pakar. Tabel kedua adalah tabel solusi, berisikan field ID, Solusi MKWAJIB, MKPIL, MKPEN, dimana pembentukan tabel solusi diperuntukan untuk menghubungkan premis premis yang telah dibentuk pada tabel knowledge untuk dicarikan solusi terbaik secara bertahap. Tahapan perancangan berikutnya adalah perancagan dengan skema physical design.

Tabel 1. Knowledge Sistem Pakar

\begin{tabular}{lllll}
\hline No & \multicolumn{1}{c}{ Field } & $\begin{array}{r}\text { Tipe } \\
\text { Data }\end{array}$ & Lebar & Keterangan \\
\hline 1 & \#ID & Text & 5 & $\begin{array}{l}\text { Primary } \\
\text { Key }\end{array}$ \\
2 & Tanya & Text & 255 & \\
3 & FaktaYA & Text & 5 & \\
4 & FaktaTIDAK & Text & 5 & \\
\hline
\end{tabular}


Arifitama, Perancangan Sistem Pakar Minat Mahasiswa Berdasarkan Kurikulum Program Studi Teknik..

Tabel 2. Solusi Sistem Pakar

\begin{tabular}{lllll}
\hline No & \multirow{2}{*}{ Field } & $\begin{array}{r}\text { Tipe } \\
\text { Data }\end{array}$ & Lebar & Keterangan \\
\hline 1 & \#ID & Text & 5 & $\begin{array}{l}\text { Primary } \\
\text { Key }\end{array}$ \\
2 & Solusi & Text & 40 & \\
3 & MKWAJIB & Text & 40 & \\
4 & MKPIL & Text & 40 & \\
5 & MPEN & Text & 40 & \\
\hline
\end{tabular}

\subsection{Perancngan Knowledge Sistem Pakar}

Binary tree digunakan sebagai model untuk $\mathrm{k}$ memudahkan pembuatan knowledge dari sistem pakar, yang dapat dilihat pada gambar 3 . Berdasarkan permodelan dari gambar 3, maka dapat kita bentuk knowledge adalah dalam bentuk pertanyaan seperti pada tabel 1 , serta penelusuran dari sistem pakar tersebut menggunakan metode forward chainning dan didapatkan beberapa premis dala bentuk pertanyaan seperti pada tabel 1 .

Tabel 3. Pertanyaan Sistem Pakar

\begin{tabular}{|c|c|}
\hline ID & PERTANYAAN \\
\hline $\mathrm{T} 1$ & $\begin{array}{l}\text { Apakah kamu suka hal yang berhubungan } \\
\text { dengan software? }\end{array}$ \\
\hline $\mathrm{T} 10$ & $\begin{array}{l}\text { Apakah kamu suka hal yang berhubungan } \\
\text { dengan pemrograman desktop/mobile }\end{array}$ \\
\hline & Apakah kamu suka hal yang berhubungan \\
\hline
\end{tabular}

\begin{tabular}{|c|c|}
\hline $\mathrm{T} 12$ & $\begin{array}{l}\text { Apakah kamu suka dengan hal yang } \\
\text { berhubungan dengan perancangan aplikasi } \\
\text { desktop/mobile? }\end{array}$ \\
\hline & Apakah kamu suka dengan hal yang \\
\hline $\mathrm{T} 13$ & berhubungan dengan data? \\
\hline $\mathrm{T} 14$ & $\begin{array}{l}\text { Apakah kamu suka dengan hal yang } \\
\text { berhubungan dengan database? }\end{array}$ \\
\hline $\mathrm{T} 15$ & $\begin{array}{l}\text { Apakah kamu suka menganalisa sebuah } \\
\text { sistem? }\end{array}$ \\
\hline $\mathrm{T} 16$ & $\begin{array}{l}\text { Apakah kamu suka dengan hal yang } \\
\text { berhubungan dengan manajemen? }\end{array}$ \\
\hline & Apakah kamu suka hal yang berhubungan \\
\hline $\mathrm{T} 17$ & dengan perolehan informasi? \\
\hline $\mathrm{T} 2$ & $\begin{array}{l}\text { Apakah kamu suka hal yang berhubungan } \\
\text { dengan hardware }\end{array}$ \\
\hline $\mathrm{T} 3$ & $\begin{array}{l}\text { Apakah kamu suka hal yang berhubungan } \\
\text { dengan komputer? } \\
\text { apakah kamu suka hal yang berhubungan }\end{array}$ \\
\hline $\mathrm{T} 4$ & $\begin{array}{l}\text { dengan coding? } \\
\text { apakah kamu suka hal yang berhubungan }\end{array}$ \\
\hline T5 & dengan perancangan? \\
\hline T6 & $\begin{array}{l}\text { Apakah kamu suka hal yang berhubungan } \\
\text { dengan data? }\end{array}$ \\
\hline $\mathrm{T} 7$ & $\begin{array}{l}\text { Apakah kamu suka hal yang berbau } \\
\text { troubleshooting? }\end{array}$ \\
\hline T8 & $\begin{array}{l}\text { Apakah kamu suka hal yang berhubungan } \\
\text { dengan jaringan? }\end{array}$ \\
\hline T9 & $\begin{array}{l}\text { Apakah kamu suka hal yang berhubungan } \\
\text { dengan pemrograman online? }\end{array}$ \\
\hline
\end{tabular}

T11 dengan perancangan aplikasi online?

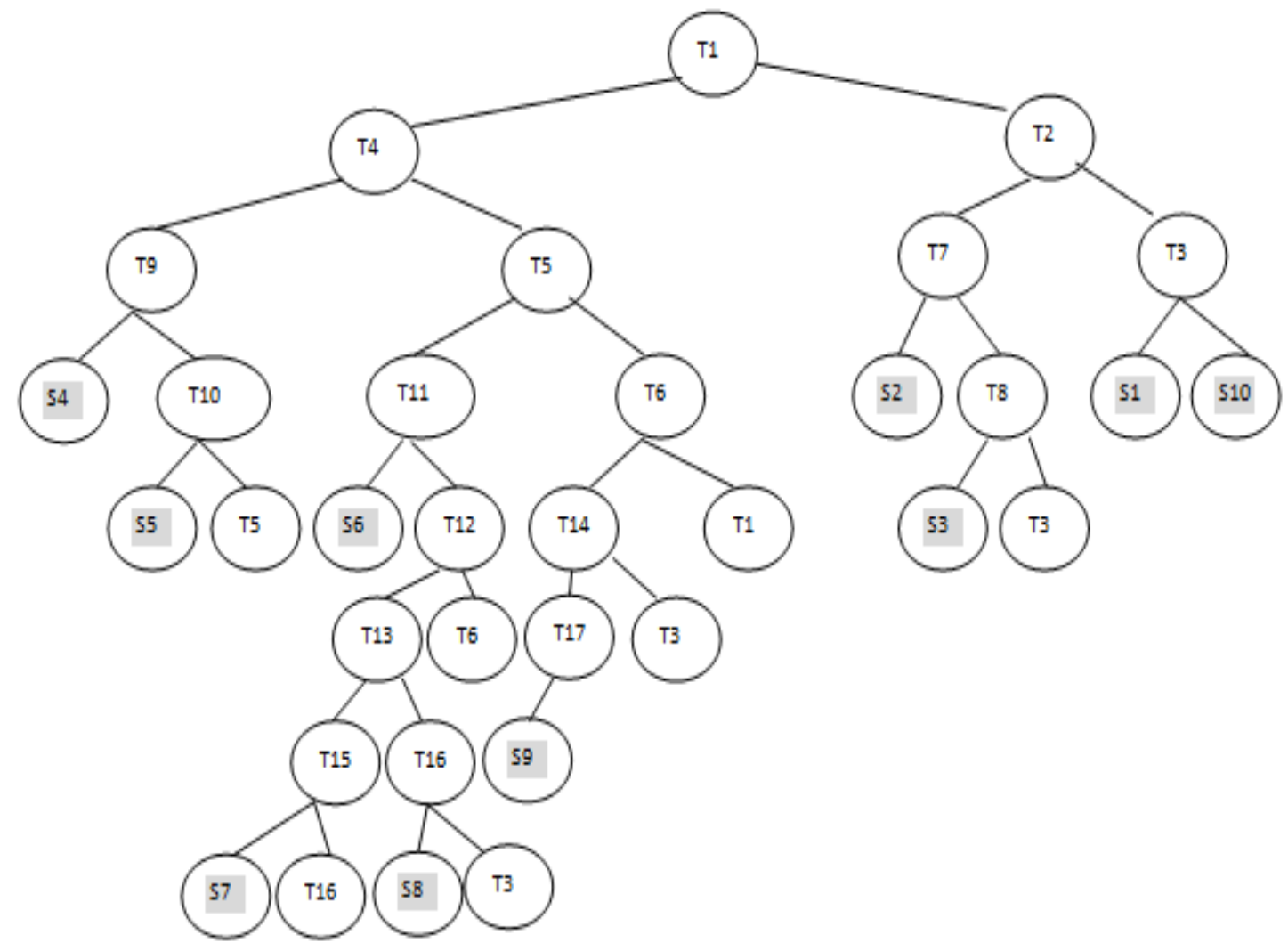

Gambar 4. Binary Tree Sistem Pakar 
Informasi premis pada tabel 3, adalah informasi yang berisikan premis serta pertanyaan yang akan tersimpan di dalam database. Premis/pertanyaan terhubung dengan beberapa perminatan yang dimiliki oleh program studi. Setelah perancangan pertanyaan selesai dibuat maka dilanjutkan dengan pembentukan fakta seperti pada tabel dan tabel. Pembentukan fakta digunakan untuk melihat rinician keterhubungan dari pemilihan awal hingga akhir dari siistem pakar.

Tabel 4. Pembentukan Fakta Benar

\begin{tabular}{|c|c|}
\hline ID & Fakta YA \\
\hline $\mathrm{T} 1$ & $\begin{array}{l}\text { Berhubungan dengan Software } \\
\text { Berhubungan dengan Desktop/Mobile }\end{array}$ \\
\hline $\mathrm{T} 10$ & $\begin{array}{l}\text { Coding } \\
\text { Berhubungan dengan perancangan }\end{array}$ \\
\hline $\mathrm{T} 11$ & Online \\
\hline $\mathrm{T} 12$ & $\begin{array}{l}\text { Berhubungan dengan perancangan } \\
\text { aplikasi desktop/mobile } \\
\text { Berhubungan dengan pengumpulan } \\
\text { data }\end{array}$ \\
\hline $\mathrm{T} 14$ & $\begin{array}{l}\text { Berhubungan dengan Database } \\
\text { Berhubungan dengan analisa kebutuhan } \\
\text { sistem }\end{array}$ \\
\hline $\mathrm{T} 16$ & $\begin{array}{l}\text { Berhubungan dengan Manajemen } \\
\text { Berhubungan dengan Perolehan }\end{array}$ \\
\hline $\mathrm{T} 17$ & Informasi \\
\hline $\mathrm{T} 2$ & Berhubungan dengan Hardware \\
\hline T3 & Umum \\
\hline $\mathrm{T} 4$ & Berhubungan dengan coding \\
\hline T5 & Berhubungan dengan perancangan \\
\hline T6 & Berhubungan dengan Data \\
\hline $\mathrm{T} 7$ & Berhubungan dengan troubleshooting \\
\hline $\mathrm{T} 8$ & Berhubungan dengan jaringan \\
\hline T9 & Berhubungan dengan online coding \\
\hline \multicolumn{2}{|c|}{ Tabel 5. Pembentukan Fakta Salah } \\
\hline ID & Fakta TIDAK \\
\hline $\mathrm{T} 1$ & $\begin{array}{l}\text { Tidak Berhubungan dengan Software } \\
\text { Tidak berhubungan dengan }\end{array}$ \\
\hline $\mathrm{T} 10$ & $\begin{array}{l}\text { desktop/mobile Coding } \\
\text { Tidak berhubungan dengan }\end{array}$ \\
\hline $\mathrm{T} 11$ & Perancangan Online \\
\hline $\mathrm{T} 12$ & $\begin{array}{l}\text { Tidak berhubungan dengan } \\
\text { perancangan aplikasi desktop/mobile } \\
\text { Tidak berhubungan dengan }\end{array}$ \\
\hline $\mathrm{T} 13$ & pengumpulan data \\
\hline $\mathrm{T} 14$ & $\begin{array}{l}\text { Tidak berhubungan dengan database } \\
\text { Tidak berhubungan dengan analisa }\end{array}$ \\
\hline $\mathrm{T} 15$ & kebutuhan sistem \\
\hline $\mathrm{T} 16$ & $\begin{array}{l}\text { Tidak berhubungan dengan Manajemen } \\
\text { Tidak berhubungan dengan Perolehan }\end{array}$ \\
\hline $\mathrm{T} 17$ & Informasi \\
\hline $\mathrm{T} 2$ & Tidak berhubungan dengan Hardware \\
\hline
\end{tabular}

\begin{tabular}{ll}
\hline T3 & Tidak Umum \\
T4 & Tidak Berhubungan dengan Coding \\
& Tidak Berhubungan dengan \\
T5 & perancangan \\
T6 & Tidak berhubungan dengan Data \\
& Tidak berhubungan dengan \\
T7 & troubleshooting \\
T8 & Tidak berhubungan dengan jaringan \\
& Tidak berhubungan dengan Online \\
T9 & Coding \\
\hline
\end{tabular}

Tabel 6. Hubungan Antar Solusi

\begin{tabular}{ccc}
\hline ID & Ya & Tidak \\
\hline T1 & T4 & T2 \\
T10 & S5 & T5 \\
T11 & S6 & T12 \\
T12 & T13 & T6 \\
T13 & T15 & T16 \\
T14 & T17 & T3 \\
T15 & S7 & T16 \\
T16 & $\mathrm{S} 8$ & $\mathrm{~T} 3$ \\
T17 & $\mathrm{S} 9$ & $\mathrm{~T} 3$ \\
T2 & T7 & T3 \\
T3 & $\mathrm{S} 1$ & $\mathrm{~S} 10$ \\
$\mathrm{~T} 4$ & $\mathrm{~T} 9$ & $\mathrm{~T} 5$ \\
$\mathrm{~T} 5$ & $\mathrm{~T} 11$ & $\mathrm{~T} 6$ \\
$\mathrm{~T} 6$ & $\mathrm{~T} 14$ & $\mathrm{~T} 1$ \\
$\mathrm{~T} 7$ & $\mathrm{~S} 2$ & $\mathrm{~T} 8$ \\
$\mathrm{~T} 8$ & $\mathrm{~S} 3$ & $\mathrm{~T} 3$ \\
$\mathrm{~T} 9$ & $\mathrm{~S} 4$ & $\mathrm{~T} 10$ \\
\hline
\end{tabular}

Penentuan urutan dari node mana yang dituju menggunakan metode forward chaining yaitu penelusuran fakta-fakta yang ada sehingga mendapatkan solusi. Adapun keterhubungan dari tiap pertanyaan dapat dilihat pada tabel 4, dimana setiap pertanyaan yang dijawab "Ya" maupun "Tidak" akan menuju ke pertanyaan selanjutnya maupun solusi yang dituju.

\subsection{Perancngan Solusi Sistem Pakar}

Perancangan solusi dari sistem pakar dilakukan sebagai bentuk penyelesain atas permasalahan yang ada, solusi pada sistem pakar adalah profesi di dunia industri di bidang TI yang mengacu berdasarkan kurikulum dari program studi. Dari kurikulum tersebut, didapatkan 9 jenis profesi di bidang teknologi informasi yang dapat dilihat pada tabel 5 
Tabel 7. Tabel Solusi Sistem Pakar

\begin{tabular}{|c|c|c|c|c|}
\hline ID & Solusi & MKWАJIB & MKPIL & MPEN \\
\hline $\mathrm{S} 1$ & Umum & - & - & - \\
\hline S2 & IT Support & MKWAJIB & MKPIL & MPEN \\
\hline S3 & Network Engineer & MKWAJIB & MKPIL & MPEN \\
\hline S4 & Web Developer & MKWAJIB & MKPIL & MPEN \\
\hline S5 & Programmer & MKWAJIB & MKPIL & MPEN \\
\hline S6 & Web Designer & MKWAJIB & MKPIL & MPEN \\
\hline S7 & System Analyst & MKWAJIB & MKPIL & MPEN \\
\hline S8 & Quality Assurance & MKWAJIB & MKPIL & MPEN \\
\hline S9 & Database Administrator & MKWAJIB & MKPIL & MPEN \\
\hline
\end{tabular}

Tabel 8.Solusi Programmer

\begin{tabular}{l}
\multicolumn{1}{c}{ PROGRAMMER } \\
\hline \multicolumn{1}{c}{ MK Wajib : } \\
\hline Mengantar pemrograman \\
Struktur Data \\
DPBO \\
\hline Grafikan : \\
Pengolahan Citra \\
Pembelajaran Mesin \\
Sistem Pakar \\
Sistem Pengambilan Keputusan \\
\hline \multicolumn{1}{c}{ MK Pendukung } \\
\hline Sistem Basis Data \\
Analisi Algoritma \\
Interaksi Manusia dan Komputer \\
Rekayasa Perangkat Lunak \\
Manajemen Proyek Perangkat Lunak \\
Penjaminan Mutu Perangkat Lunak \\
\hline
\end{tabular}

Field MK WAJIB adalaha matakuliah wajib, field MK PIL adalah mata kuliah pilihan dan MK PEN adalah Mata Kuliah Pendukung. Berikut pada tabel 6 adalah contoh dari solusi programmer beserta rincian mata kuliah.

\subsection{Implementasi}

Implementasi dari aplikasi sistem pakar dengan solusi akhir profesi Web Developer dilaksanakan dengan cara pertama dengan menekan tombol diagnosa di menu utama, yang kemudian akan muncul pertanyaan pertanyaan yang harus di jawab oleh pengguna dengan jawaban "Ya" maupun "Tidak" seperti pada gambar 5, gambar 6, dan gambar 7.
Apakah kamu suka hal yang berhubungan dengan software?

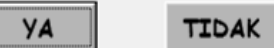

Gambar 5. Diagnosa pertanyaan 1

apakah kamu suka hal yang berhubungan dengan coding?

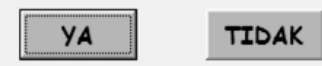

SELESAI

Gambar 6. Diagnosa pertanyaan 2

Apakah kamu suka hal yang berhubungan dengan pemrograman online?

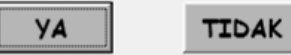

SELESAI

Gambar 7. Diagnosa pertanyaan 3

Setelah proses menjawab pertanyaan akan tercetak hasil akhir atau solusi dari sistem pakar dimana pengguna juga akan mendapatkan informasi mengenai matakuliah apa saja yang perlu mahasiswa perhatikan untuk mendukung perminatan berdasarkan solusi yang diberikan.

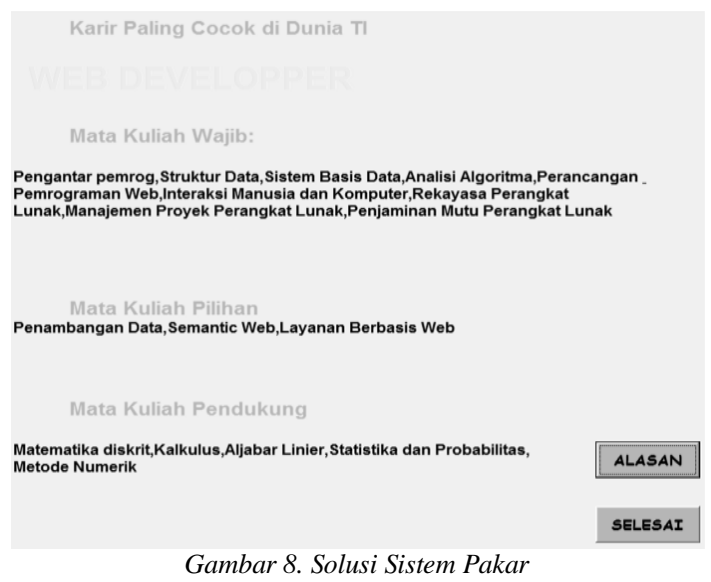


Pada form analisa yang terletak di gambar memperlihatkan rincian dari seluruh pertanyaan yang dijawab oleh mahasiswa secara satu persatu hingga kesimpulan dari solusi yang diberikan. Informasi yang didapatkan pada form analisa pada gambar 8, diharapkan dapat digunakan oleh mahasiswa untuk memahami alasan dari solusi yang diberikan oleh sistem pakar.

Contoh implementasi ke dua dari aplikasi sistem pakar adalah solusi untuk profesi IT Support. Penggunaan sama seperti halnya pada penjelasan sebelumnya bahwa pengguna diharuskan menjawab pertanyaan pertanyaan seperti yang ditampilkan pada gambar 10, gambar 11, dan gambar 12, diman akan menghasilkan sebuah solusi seperti pada gambar 13 dan 14 .

Contoh implementasi ke tiga dari aplikasi sistem pakar adalah solusi untuk profesi Database. Penggunaan sama seperti halnya pada penjelasan sebelumnya bahwa pengguna diharuskan menjawab pertanyaan pertanyaan seperti yang ditampilkan pada gambar 15, gambar 16, dan gambar 17, gambar 18 dan gambar 19, dimana akan menghasilkan sebuah solusi seperti pada gambar 20 dan 21.

\section{Oleh Karena :}

Berhubungan dengan Software

Berhubungan dengan coding

Berhubungan dengan online coding

maka hasil diagnosa adalah :

WEB DEVELOPPER

Gambar 9. Alasan Sistem Pakar

Apakah kamu suka hal yang berhubungan dengan software?

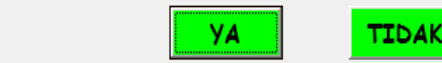

SELESAI

Gambar 10. Pertanyaan 1 IT Support

Apakah kamu suka hal yang berhubungan dengan hardware

YA

TIDAK

SELESAI

Gambar 11. Pertanyaan 2 IT Support

Apakah kamu suka hal yang berbau troubleshooting?

\section{YA TIDAK}

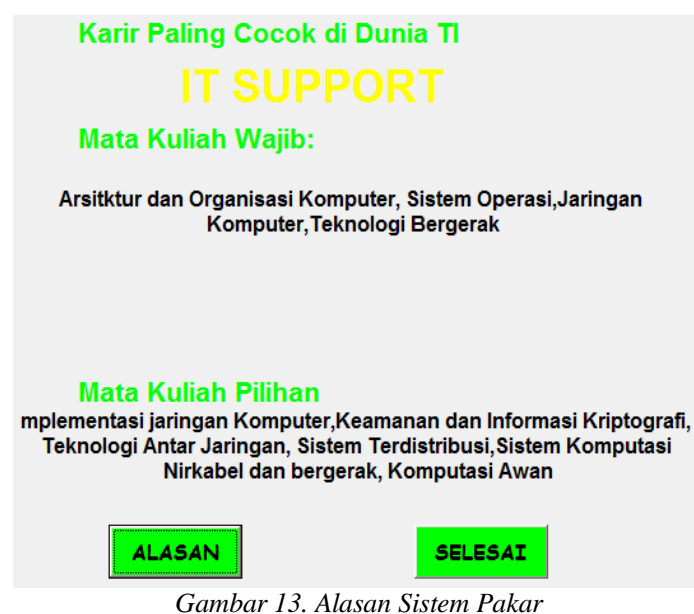

\section{Oleh Karena :}

Tidak Berhubungan dengan Software

Berhubungan dengan Hardware

Berhubungan dengan troubleshooting

maka hasil diagnosa adalah :

IT SUPPORT

\section{SELESAI}

Gambar 14. Alasan Sistem Pakar

Apakah kamu suka hal yang berhubungan dengan software?

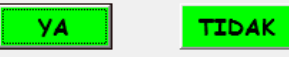

SELESAI

Gambar 15. Pertanyaan 1

apakah kamu suka hal yang berhubungan dengan coding?

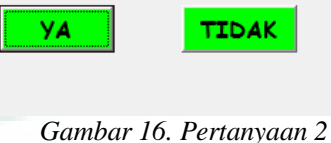

SELESAI

Gambar 16. Pertanyaan 2

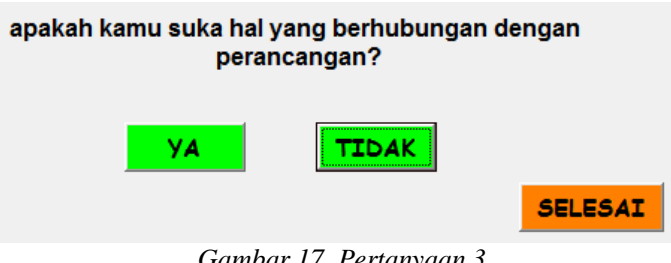

Apakah kamu suka hal yang berhubungan dengan data?

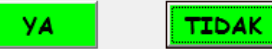

SELESAI

Gambar 12. Pertanyaan 3 IT Support 


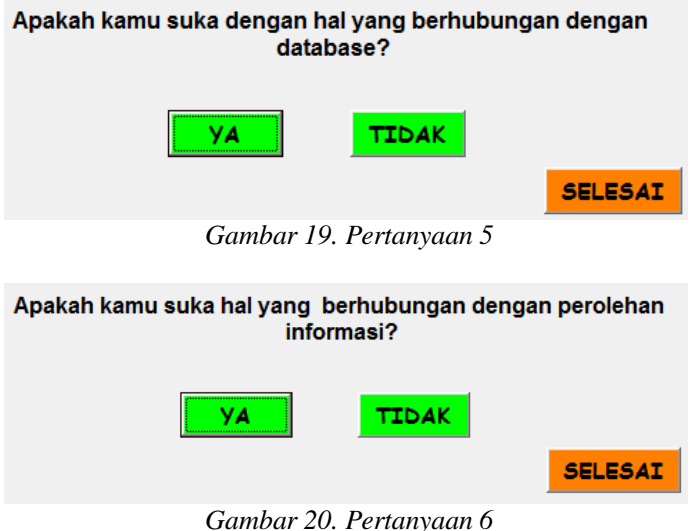

Karir Paling Cocok di Dunia TI

\section{Mata Kuliah Wajib:}

Sistem Basis Data

Mata Kuliah Pilihan

Penambangan Data,Perolehan Informasi,Administrasi Basis Data

$$
\text { ALASAN }
$$

Gambar 21. Alasan Sistem Pakar

\section{SIMPULAN dan SARAN}

Aplikasi sistem pakar perminatan mahasiswa pada bidang teknologi informasi yang mengacu pada kurikulum teknik informatika telah mampu membantu mahasiswa program studi teknik informatika dalam menentukan pilihan bidang studi yang dipilih. Namun tentunya masih banyak pengembangan yang dapat dilakukan untuk penelitian lebih lanjut yaitu mengukur kecocokan kebutuhan indusrti dengan hasil lulusan universitas.

\section{DAFTAR RUJUKAN}

Arnaka Sandy Putra, 2013. Sistem Pakar Pendeteksi Penyakit Gigi Berlubang Dengan Metode Forward Chaining Pada Klinik Dokter Gigi "Ani Subekti" Semarang, TransIT Vol 1 no 2, Semarang

Agustinus Prasetyo Mahardika, 2013. Sistem Pakar Pendeteksi Penyakit Kulit Pada Manusia Dengan Metode Forward Chaining, TransIT Vol 1 no 2, Semarang

Aprilia Sulistyohati, Taufiq Hidayat, 2008. Aplikasi Sistem Pakar Diagnosa Penyakit Ginjal Dengan Metode Dempster-Shafer, Seminar Nasional Aplikasi Teknologi Informasi (SNATI), 21 Juni, Jogjakarta

Durkin, John, Expert System: Design and Development 1st edition. 1994

Giarratano Joseph C., Riley Gary D, Expert Systems: Principles and Programming, Fourth Edition, Course Technology

Gusti Ayu Kadek Tuti.A, Rosa Delima, Umi Proboyekti, Penerapan Forward Chainning Pada Program Diagnosa Anak Penderita Autisme, Jurnal Informatika, Vol 5, No 2, November, 2009

Kusrini, Sistem Pakar Teori dan Aplikasi, Penerbit Andi Publisher, 2006

Kusumadewi, S., Artificial Intellegence (Teori dan Aplikasinya), Penerbit Graha Ilmu, Yogjakarta, 2003

Luther Latumakulita, Chriestie E. J. C. Montolalu, 2011. Sistem Pakar Pendiagnosa Penyakit Ginjal, Jurnal Ilmiah Sains Vol 11, April.

Uky Yudatama, 2008. Sistem Pakar untuk Diagnosis Kerusakan Mesin Mobil Panther Berbasis Mobil,Jurnal Teknologi, Volume 1 Nomor 2, Desember. 